Int. Agrophys., 2020, 34, 115-121

\title{
ABA alleviated soybean seedling stress exposed to UV-C radiation
}

\author{
Liyan Yang ${ }^{1}$, Ning Gao ${ }^{1}$, Yashu Yang ${ }^{1}$, Yurong Zhang ${ }^{1}$, Jing Gao ${ }^{1}$, and Yi Sun ${ }^{2}$ * \\ ${ }^{1}$ Life Science Department, Shanxi Normal University, Linfen, China \\ ${ }^{2}$ Biotechnology Research Center, Shanxi Academy of Agricultural Sciences, Taiyuan, China
}

Received June 7, 2019; accepted October 21, 2019

\begin{abstract}
In order to understand the roles of abscisis acid in soybean exposed to UV-C radiation, soybean seedlings were exposed to UV-C radiation and ABA was applied. The chlorophyll content, active oxygen metabolism and flavonoids content of soybean seedlings were investigated. The present study revealed that UV-C radiation significantly attenuated the chlorophyll content and suppressed PSII activity. It was observed that the contents of $\mathrm{H}_{2} \mathrm{O}_{2}$, malondialdehyde and $\mathrm{O}_{2}^{-}$were markedly increased, and the activities of antioxidant enzymes such as superoxide dismutase, peroxidase and catalase were enhanced, so were the flavonoids content, whereas the seedling height and biomass were significantly reduced. ABA application improved the activities of superoxide dismutase, peroxidase, catalase and the contents of flavonoids, decreased the contents of $\mathrm{H}_{2} \mathrm{O}_{2}, \mathrm{MDA}$ and $\mathrm{O}_{2}^{-}$, and also increased the chlorophyll content and enhanced PSII performance, thus enhancing biomass accumulation. The results suggested that ABA alleviated UV-C damage to soybean seedlings by reducing ROS generation and enhancing antioxidase activity. The isoflavones daidzin and genistein were significantly responsive to UV-C.

Keyw ords: ultraviolet-C, ABA, active oxygen metabolism, flavonoids, soybean
\end{abstract}

\section{INTRODUCTION}

During the long process of evolution, plants developed a number of efficient defence systems to alleviate the damage caused by strong ultraviolet light (UV) including protective structures, like hairs, trichomes and epicuticular wax, which enhance epidermal reflectance, also, compounds such as flavonoids, which are able to absorb UV and eliminate reactive oxygen species (ROS) (Hollosy, 2002). The antioxidase system, which includes superoxide dismutase (SOD), peroxidase (POD) and catalase (CAT), also alleviates oxidation damage (Mittova et al., 2002).
UV-B (wavelengths from 280 to $320 \mathrm{~nm}$ ) may cause conformational breakages of proteins and nucleic acids and has long been recognized as an environmental stressor to organisms. However, after the discovery of UV-B photoreceptor UVR8 in Arabidopsis thaliana, perceptions concerning the biological impact of UV-B radiation on plants have changed from a generic stressor to a specific regulator (Jansen and Bornman, 2012). UV-C (200-280 $\mathrm{nm}$ ), has an antimicrobial potential and a damaging effect on plants. However, evidence is mounting which indicates that UV-C light may also have beneficial effects on plants and harvested plant organs, like reducing chilling damage in pepper (Vicente et al., 2005), increasing the antioxidant capacity of mushrooms during storage (Wu et al., 2016) and adding value to edible broccoli parts (Formica-Oliveira et al., 2017). Indeed, it has been known for more than 40 years, that the UV activity spectrum increases sharply in the UV-C region (Setlow, 1974). It may therefore be beneficial to study the effects of UV-C light in more depth.

Phytohormones are essential regulating substances for plant growth and development, and they are also are triggers for the expression of adversity resistance genes (Thiruvengadam et al., 2015). Among phytohormones, abscisic acid (ABA) is a vital signalling molecule in plants for adapting to stresses such as drought, high salinity and UV-B radiation (Tossi et al., 2012; Amjad et al., 2014; Yang et al., 2014). Akito et al. (2015) reported that in Marchantia polymorpha, UV-C markedly elevates ABA levels and stimulates the biosynthesis of bisbibenzyls, which are characteristic secondary metabolites in liverworts and have various biological functions such as antimicrobial, anticancer,

(C) 2020 Institute of Agrophysics, Polish Academy of Sciences 
and antioxidant activities (Harrowven and Kostiuk 2012; Asakawa et al., 2013). Urban et al. (2016) have theorized that UV-B and UV-C may initiate essentially the same signalling pathways, due to the fact that UV-B and UV-C radiation seem to be the cause of similar effects.

Soybean (Glycine max) is one of the important leguminous crops in the world, its high contents of protein and flavonoids have given it the status of an economically valuable crop. It was reported that the level of isoflavones in soybean was increased by UV-B radiation treatment (Ma et al., 2018). To date, the responses of soybean to UV-C radiation have not been studied. Therefore, in the present study, for the first time, we investigated the effects of UV-C on soybean vigour, wherein chlorophyll content, photosystem II (PSII) activity, active oxygen metabolism, isoflavone accumulation and seedling biomass were analysed, also, the effects of exogenous ABA on soybean under UV-C radiation were explored.

\section{MATERIALS AND METHODS}

Soybean (Glycine max) seeds (cv. Jin 36) were provided by the Wheat Research Institute, Shanxi Academy of Agricultural Sciences (SAAS), China. Uniform soybean seeds were selected, sterilized for $10 \mathrm{~min}$. with $0.1 \% \mathrm{HgCl}_{2}$ and rinsed for $50 \mathrm{~min}$. with running tap water. The plants were grown in pots $(15 \times 20 \mathrm{~cm})$ in a growth chamber at $25^{\circ} \mathrm{C}$ and $70 \%$ relative humidity with an illumination value of $600 \mu \mathrm{mol} \mathrm{m}^{-2} \mathrm{~s}^{-1}$ according to the light / dark period as given in Table 1. Soybean management was carried out according to the guideline provided for the cultivar. There were 3 treatments with 3 replicates and twenty seedlings were used for each one. When the first compound leaf emerged, UV-C irradiation treatment was applied. The intensity of UV-C radiation was $0.284 \mathrm{~mW} \mathrm{~cm}^{-2}$, it was generated by a filtered lamp (15W, $254 \mathrm{~nm}$, Qin brand, Baoji Lamp Factory, Baoji City, China), which shone for 20 min per day. The lamps were hung $40 \mathrm{~cm}$ above the plants and the irradiation intensity was altered by adjusting the distance between the lamps and the pots.

Exogenous ABA ( $10 \mathrm{mg} \mathrm{L}^{-1}$, with $0.5 \%$ Tween-20) was applied at 8:00 pm to prevent $\mathrm{ABA}$ degradation from strong light. ABA was smeared onto the seedling leaves every 2 days. The same amount of distilled water was applied for the control and UV-C treatment.

Table 1. Light / dark period of irradiation treatments

\begin{tabular}{lccc}
\hline Treatment & Light & $\begin{array}{c}\text { UV-C } \\
\text { irradiation }\end{array}$ & Dark \\
\hline $\mathrm{CK}$ & & - & \\
$\mathrm{C}$ & $12 \mathrm{~h} \mathrm{~d}^{-1}$ & $20 \min 2 \mathrm{~d}^{-1}$ & $12 \mathrm{~h} \mathrm{~d}^{-1}$ \\
$\mathrm{C}+\mathrm{ABA}$ & & & \\
\hline
\end{tabular}

$\mathrm{CK}$ - distilled water treatment without $\mathrm{UV}-\mathrm{C}$ radiation, $\mathrm{C}-\mathrm{UV}-\mathrm{C}$ radiation, $\mathrm{C}+\mathrm{ABA}-\mathrm{ABA}$ application $+\mathrm{UV}-\mathrm{C}$ radiation.
Fifty days after seedling emergence, ten seedlings per replicate were randomly taken from each treatment, their height and dry weight were measured and the means were recorded. Leaves from the same position on the plants were collected for the indices measurements described below.

A chlorophyll fluorescence measurement was made using a portable pulse-modulated fluorometer (PAM-2000, Walz, Effeltrich, Germany) with top leaves of seedlings. Maximum photochemical conversion efficiency ( $\mathrm{Fv} / \mathrm{Fm})$, the non-photochemical quenching coefficient (NPQ) and the actual quantum yield of PSII photochemistry (Yield) were recorded. Then the leaves were collected and the chlorophyll content and chlorophyll $\mathrm{a} / \mathrm{b}$ were measured according to Lee (2000).

The MDA content was determined using the TBA method. The supernatant of the leaf grinding solution was precipitated with $0.6 \%(\mathrm{w} / \mathrm{v}) 2$-thiobarbituric acid. The reaction mixture was incubated in a water-bath shaker at $100^{\circ} \mathrm{C}$ for $30 \mathrm{~min}$. The amount of MDA present was estimated in the form of micromole per gram FW. The $\mathrm{H}_{2} \mathrm{O}_{2}$ content was determined using the titanium sulphate colorimetric method. The production rate of superoxide anion $\left(\mathrm{O}_{2}^{-}\right)$was determined using the hydroxylamine method (Ye and Zhu, 2007). Briefly, fresh leaf sample was homogenized in phosphate buffer $\left(65 \mathrm{mmol} \mathrm{L}^{-1}, \mathrm{pH} 7.8\right)$, then centrifuged. The supernatant was mixed with hydroxylamine hydrochloride phosphate buffer and kept at $25^{\circ} \mathrm{C}$ for $20 \mathrm{~min}$. $\alpha$-Naphthylamine and aminobenzene sulphonic acid were used as chromogenic agents and kept at $25^{\circ} \mathrm{C}$ for $20 \mathrm{~min}$. The absorbance of the supernatant was measured at $530 \mathrm{~nm}$ by spectrophotometer.

SOD activity was determined based on the inhibition of the photochemical reduction of nitroblue tetrazolium (NBT), and one unit of SOD activity was defined as the quantity of the enzyme required to inhibit the reduction of NBT by $50 \%$. POD activity was measured using the guaiacol oxidation method where guaiacol oxidation was measured at $470 \mathrm{~nm}$ and the value was precisely calculated. CAT activity was estimated through the measurement of $\mathrm{H}_{2} \mathrm{O}_{2}$ consumption wherein the decrease in absorbance at $240 \mathrm{~nm}$ for $120 \mathrm{~s}$ was recorded.

The content of flavonoids was determined spectrophotometrically based on the formation of a flavonoids-aluminum complex (Zhou et al., 2005), the absorbance was measured at $420 \mathrm{~nm}$, the total flavonoids content was shown in the form of the rutin ( $\mu \mathrm{g} \mathrm{g}^{-1}$ extract) amount. Total protein content was quantified according to Bradford (1976) where BSA (bovine serum albumin) was used as the standard.

HPLC analyses were performed on a Waters high performance liquid chromatography system (Waters Corporation, USA) equipped with a Model Delta 600 pump, 2996 photodiode array detector and Millennium 32 system software. The column used was a HIQ Sil C18V reversed-phase column $(250 \mathrm{Mm} \times 4.6 \mathrm{~mm}$ I.D., Kya Tech, Hachioji City, Japan) and the mobile phase was a mixture of solvent A 
(methanol) and B (0.1\% phosphoric acid in water, v/v), according to a linear gradient with a duration of $60 \mathrm{~min}$, at a flow rate of $1.0 \mathrm{~mL} \mathrm{~min}^{-1}$. The signals at $254 \mathrm{~nm}$ were collected and recorded, and the sample quantity was $10 \mu \mathrm{L}$. Four types of isoflavones: daidzin, genistin, daidzein and genistein were produced by Hefei Bomei Biotechnology Co. Ltd, China.

Statistical significance was estimated at $\mathrm{p}<0.05$ according to Duncan's multiple range test. All data were given as mean $\pm \mathrm{SD}$.

\section{RESULTS}

In order to understand how UV-C and ABA influence chlorophyll synthesis, chlorophyll content and chlorophyll $\mathrm{a} / \mathrm{b}$ were determined. UV-C radiation reduced the chlorophyll content and chlorophyll $\mathrm{a} / \mathrm{b}$, which was 43.5 and $28.1 \%$ lower than the $\mathrm{CK}$. The application of ABA increased chlorophyll content and chlorophyll a/b more than those in the $\mathrm{C}$ group, which were 24.5 and $26.8 \%$ higher, respectively, but still lower than the control (Fig. 1).

We measured the maximum photochemical conversion efficiency, defined as Fv/Fm and the actual quantum yield of PSII photochemistry (yield) in order to assess the susceptibility of seedlings from different treatments to photoinhibition. The lowest $\mathrm{Fv} / \mathrm{Fm}$ and actual quantum yield presented in $\mathrm{C}$ group, which indicated UV-C radiation depressed the photochemical efficiency of seedling leaves. ABA displayed an alleviated damaging effect on
PSII where Fv/Fm and Yield increased by 19.0 and $47.1 \%$ respectively, compared to the control. The non-photochemical quenching coefficient (NPQ) was also remarkably depressed $(\mathrm{p}<0.05)$ by UV-C radiation, thereby indicating the lower capability of heat emission, and therefore, the reduced photoprotection capacity of PSII. The application of ABA partially alleviated photoinhibition and enhanced the protection of PSII, in which Fv/Fm, Yield and NPQ were increased by $10.9,40.2$, and $26.9 \%$, respectively, compared with those in the $\mathrm{C}$ group $(\mathrm{p}<0.05)$ (Table 2).

In order to clarify the ROS generation of seedlings under UV-C radiation, we determined the $\mathrm{O}_{2}^{-}$production rate, $\mathrm{H}_{2} \mathrm{O}_{2}$ and MDA contents. The lowest $\mathrm{O}_{2}^{-}$production rate, $\mathrm{H}_{2} \mathrm{O}_{2}$ and MDA contents were observed in the control. Under UV-C radiation, the $\mathrm{O}_{2}^{-}$production rate, $\mathrm{H}_{2} \mathrm{O}_{2}$ and MDA contents were enhanced significantly $(p<0.05)$ compared to the control. ABA reduced the $\mathrm{H}_{2} \mathrm{O}_{2}$ and MDA contents $(p<0.05)$ compared with those values under UV-B radiation alone $(\mathrm{p}<0.05)$ (Fig. 2), although the $\mathrm{O}_{2}^{-}$production rate $(\mathrm{p}>0.05)$ was not affected.

In order to understand how the antioxidant enzymes responded under UV-C radiation, the activities of SOD, POD and CAT were assayed. The results showed that they all increased compared with the control. ABA application exerted positive effects on their activities, which were 10.7, 11.9 , and $19.3 \%$ higher than those in the $\mathrm{C}$ groups, and 40.1 , 44.5 , and $26.8 \%$ higher than those in the control (Fig. 3).
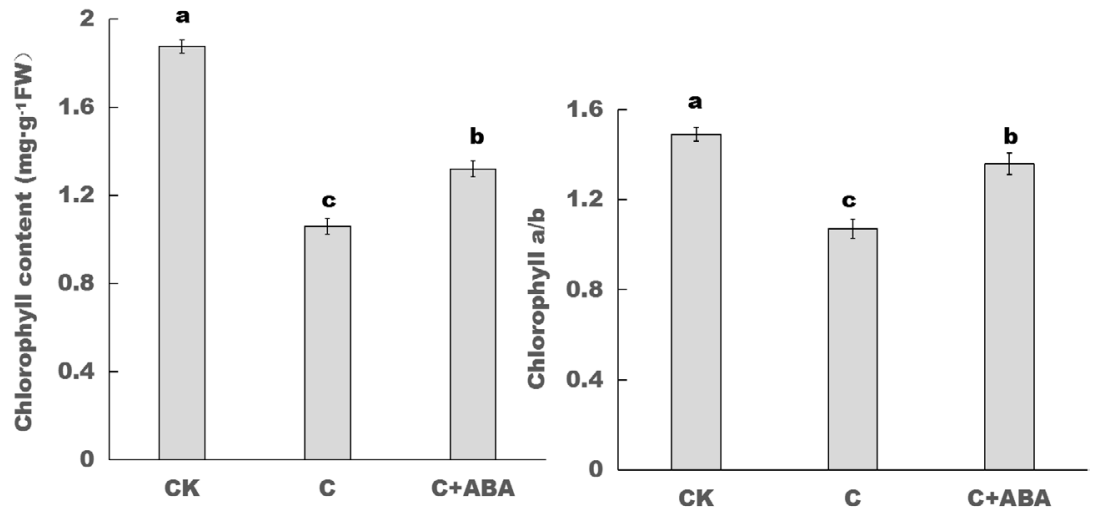

Fig. 1. Effects of exogenous $\mathrm{ABA}$ on chlorophyll content and $\mathrm{Chl} \mathrm{a} / \mathrm{b}$ in seedlings under UV-C radiation. Each bar is the mean $\pm \mathrm{SD}$ $(n=3)$ for each treatment. Bars with different letters denote significant differences at $\mathrm{p}<0.05$. CK - distilled water treatment without $\mathrm{UV}-\mathrm{C}$ radiation, $\mathrm{C}-\mathrm{UV}-\mathrm{C}$ radiation, $\mathrm{C}+\mathrm{ABA}-\mathrm{UV}-\mathrm{C}$ radiation $+\mathrm{ABA}$ application.

Table 2. Effects of exogenous ABA on Fv/Fm, yield and NPQ in seedling leaves under UV-C radiation

\begin{tabular}{lccc}
\hline Treatment & Fv/Fm & Yield & NPQ \\
\hline CK & $0.812 \pm 0.021 \mathrm{a}$ & $0.561 \pm 0.010 \mathrm{a}$ & $1.863 \pm 0.070 \mathrm{a}$ \\
$\mathrm{C}$ & $0.658 \pm 0.019 \mathrm{c}$ & $0.296 \pm 0.015 \mathrm{c}$ & $1.113 \pm 0.056 \mathrm{c}$ \\
$\mathrm{C}+\mathrm{ABA}$ & $0.730 \pm 0.016 \mathrm{~b}$ & $0.415 \pm 0.021 \mathrm{~b}$ & $1.412 \pm 0.083 \mathrm{~b}$ \\
\hline
\end{tabular}

Fv/Fm represents the maximal quantum yield of PSII. Yield represents the actual quantum yield of PSII photochemistry, and NPQ represents the non-photochemical quenching coefficient. 

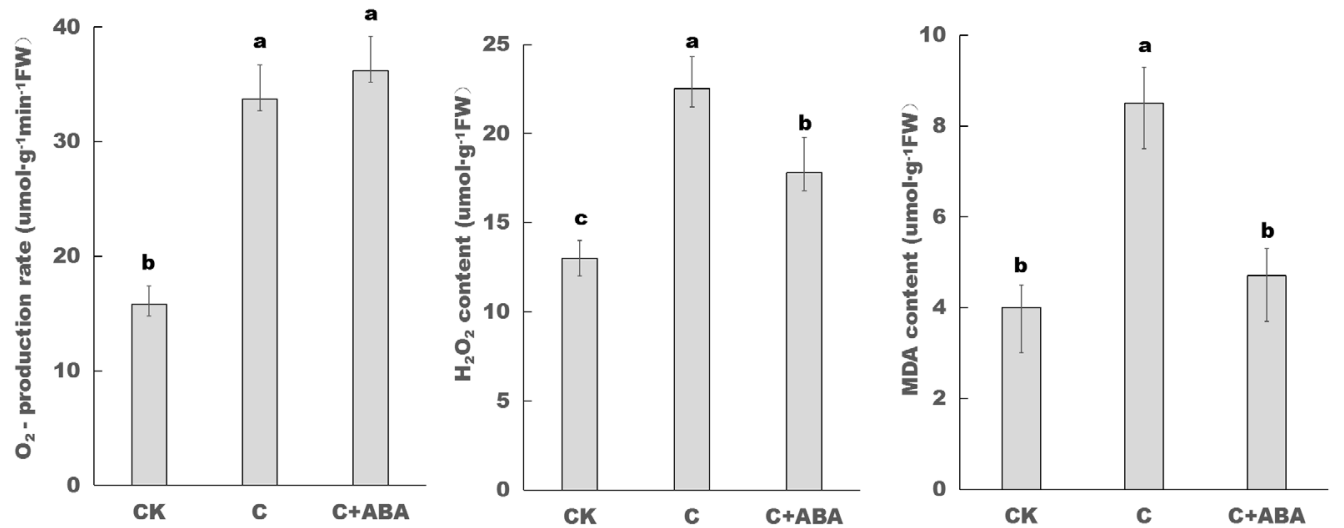

Fig. 2. Effects of exogenous $\mathrm{ABA}$ on $\mathrm{O}_{2}^{-}$production rate, $\mathrm{H}_{2} \mathrm{O}_{2}$ and MDA contents in the leaves of seedlings under UV-C radiation. Each bar is the mean $\pm \mathrm{SD}(\mathrm{n}=3)$ for each treatment. Bars with different letters denote significant differences at $\mathrm{p}<0.05$. CK - distilled water treatment without $\mathrm{UV}-\mathrm{C}$ radiation, $\mathrm{C}-\mathrm{UV}-\mathrm{C}$ radiation, $\mathrm{C}+\mathrm{ABA}-\mathrm{UV}-\mathrm{C}$ radiation $+\mathrm{ABA}$ application.
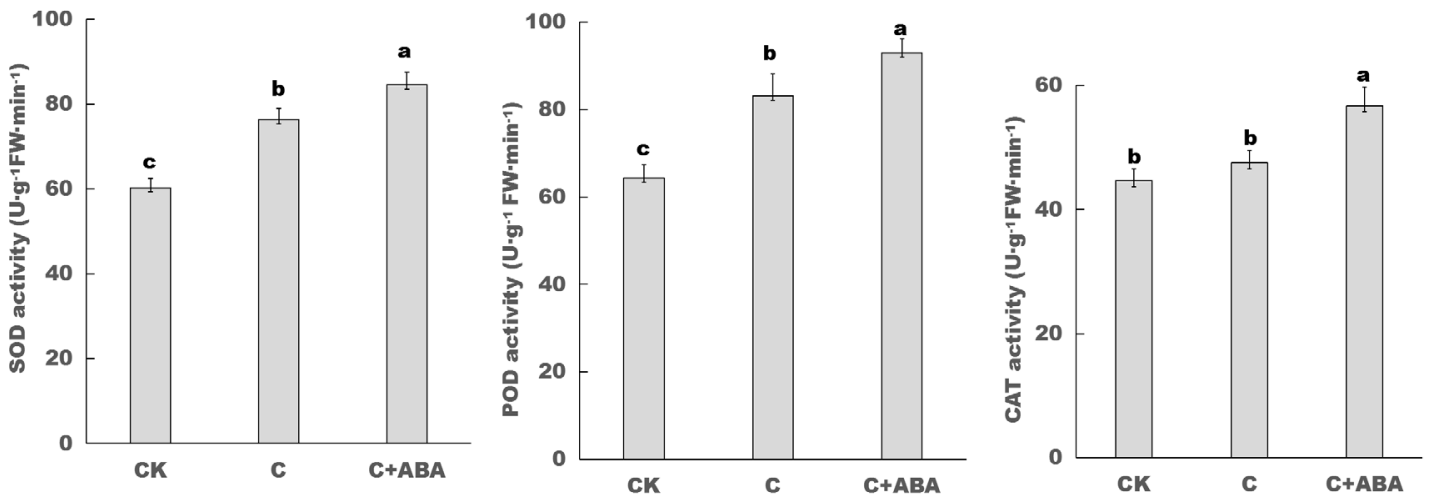

Fig. 3. Effects of exogenous ABA on the activity of SOD, POD and CAT in seedlings under UV-C radiation. Each bar is the mean \pm SD $(n=3)$ for each treatment. Bars with different letters denote significant differences at $\mathrm{p}<0.05$. CK - distilled water treatment without $\mathrm{UV}-\mathrm{C}$ radiation, $\mathrm{C}-\mathrm{UV}-\mathrm{C}$ radiation, $\mathrm{C}+\mathrm{ABA}-\mathrm{UV}-\mathrm{C}$ radiation $+\mathrm{ABA}$ application.

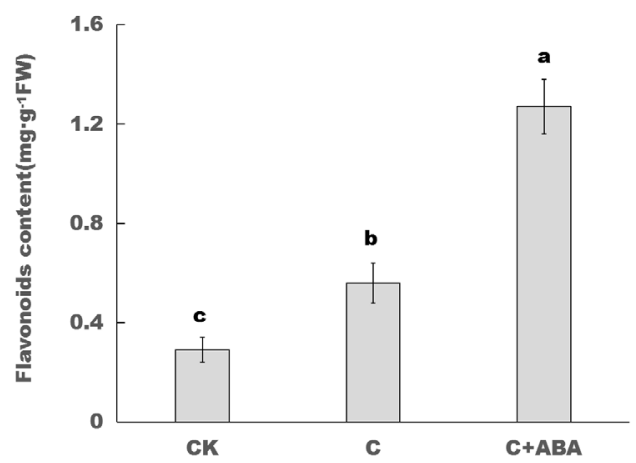

Fig. 4. Effects of exogenous $A B A$ on flavonoids contents in seedlings under UV-C radiation. Each bar is the mean $\pm \mathrm{SD}(\mathrm{n}=3)$ for each treatment. Bars with different letters denote significant differences at $\mathrm{p}<0.05$. $\mathrm{CK}-$ distilled water treatment without $\mathrm{UV}-\mathrm{C}$ radiation, $\mathrm{C}-\mathrm{UV}-\mathrm{C}$ radiation, $\mathrm{C}+\mathrm{ABA}-\mathrm{UV}-\mathrm{C}$ radiation + ABA application.
The contents of flavonoids significantly increased $(\mathrm{p}<0.05)$ with UV-C treatment, which was $92 \%$ higher than that in the control; ABA application promoted the production of flavonoids, which was $336.4 \%$ higher than that in the $\mathrm{C}$ group and $127.2 \%$ higher than the control (Fig. 4).

The soybean isoflavone contents were determined by HPLC with the 4 isoflavones as standards (Fig. 5). We found that the content of daidzin, genistin, daidzein and genistein in seedling leaves increased significantly with UV-C treatment $(p<0.05)$ compared to the control, while the application of ABA reduced the generation of isoflavones, which were not significantly different from the control $(p>0.05)$ (Tables 3 and 4).

Soybean biomass significantly decreased under UV-C radiation, which was $37.2 \%$ lower in $\mathrm{C}$ group compared to the control $(\mathrm{p}<0.05)$; the inhibition effect was greatly alleviated by the presence of ABA, which resulted in biomass production that was $25.8 \%$ higher than that of $\mathrm{C}$ group 

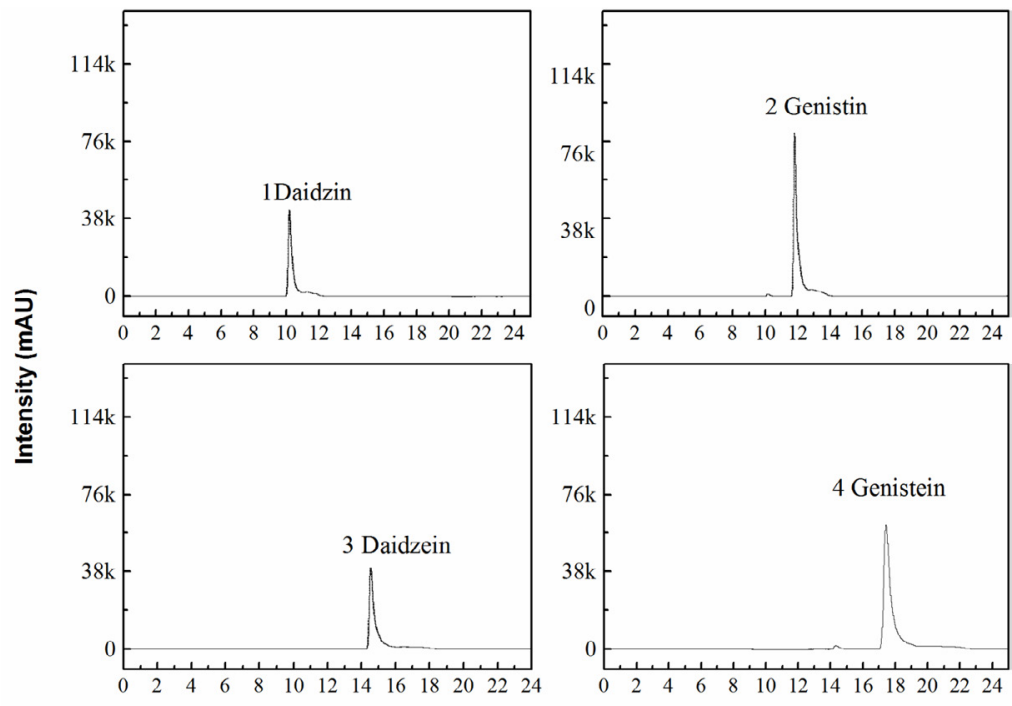

Time (min)

Fig. 5. Chromatogram of the standard soybean isoflavones.

Table 3. Calibration curves for the 4 relevant isoflavones

\begin{tabular}{lccc}
\hline Compound & Calibration curve & Linear range $/ \mu \mathrm{g}$ & $\mathrm{r}^{2}$ \\
\hline Daidzin & $\mathrm{Y}=24911.32 \mathrm{x}-48926.5$ & $2.075-101.5$ & 0.9993 \\
Genistin & $\mathrm{Y}=42189.05 \mathrm{x}-79934.0$ & $2.450-49.0$ & 0.9958 \\
Daidzein & $\mathrm{Y}=31256.82 \mathrm{x}-172436.5$ & $4.250-85.00$ & 0.9985 \\
Genistein & $\mathrm{Y}=18180.75 \mathrm{x}-93613.3$ & $3.175-183.5$ & 0.9995 \\
\hline
\end{tabular}

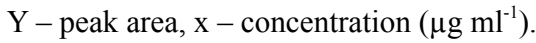

Table 4. Effects of exogenous ABA on isoflavone content in seedlings leaves under UV-C radiation

\begin{tabular}{lcccc}
\hline & \multicolumn{3}{c}{ Isoflavone $\left(\mu \mathrm{g} \mathrm{g}^{-1}\right)$} \\
\cline { 2 - 5 } Treatment & $\begin{array}{c}\text { Daidzin } \\
(10.204)\end{array}$ & $\begin{array}{c}\text { Genistin } \\
(11.821)\end{array}$ & $\begin{array}{c}\text { Daidzein } \\
(14.552)\end{array}$ & $\begin{array}{c}\text { Genistein } \\
(17.430)\end{array}$ \\
\hline $\mathrm{CK}$ & $0.51 \pm 0.04 \mathrm{~b}$ & $0.9 \pm 0.003 \mathrm{~b}$ & $1.42 \pm 0.008 \mathrm{~b}$ & $1.09 \pm 0.006 \mathrm{~b}$ \\
$\mathrm{C}$ & $4.07 \pm 0.007 \mathrm{a}$ & $2.45 \pm 0.009 \mathrm{a}$ & $3.20 \pm 0.006 \mathrm{a}$ & $7.03 \pm 0.009 \mathrm{a}$ \\
$\mathrm{C}+\mathrm{ABA}$ & $0.53 \pm 0.006 \mathrm{~b}$ & $0.64 \pm 0.002 \mathrm{~b}$ & $1.20 \pm 0.003 \mathrm{~b}$ & $1.82 \pm 0.008 \mathrm{~b}$ \\
\hline
\end{tabular}

$\mathrm{CK}$ - distilled water treatmen without $\mathrm{UV}-\mathrm{C}$ radiation, $\mathrm{C}-\mathrm{UV}-\mathrm{C}$ radiation, $\mathrm{C}+\mathrm{ABA}-\mathrm{ABA}$ application $+\mathrm{UV}-\mathrm{C}$ radiation.
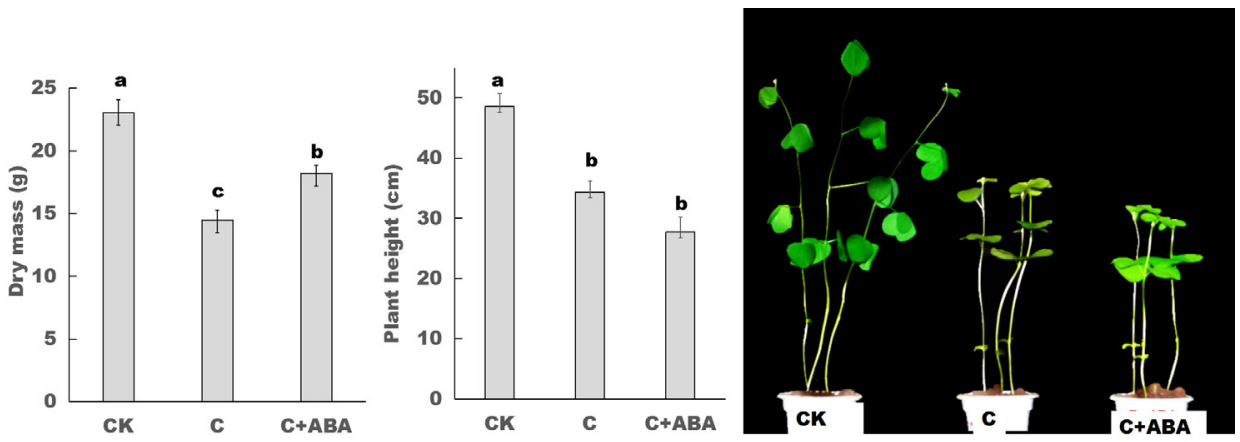

Fig. 6. Effects of exogenous ABA on biomass accumulation and the height of seedlings under UV-C radiation. Each bar is the mean $\pm \mathrm{SD}(\mathrm{n}=3)$ for each treatment. Bars with different letters denote significant differences at $\mathrm{p}<0.05$. CK - distilled water treatment without $\mathrm{UV}-\mathrm{C}$ radiation, $\mathrm{C}-\mathrm{UV}-\mathrm{C}$ radiation, $\mathrm{C}+\mathrm{ABA}-\mathrm{UV}-\mathrm{C}$ radiation $+\mathrm{ABA}$ application. 
though still lower than the control. Among the 3 groups, the highest seedling height was observed in the control, followed by that of the $\mathrm{C}$ group, and the lowest height was observed in the $\mathrm{C}+\mathrm{ABA}$ group, in which they decreased by 42.9 and $19.3 \%$, respectively, compared with that in the CK and $\mathrm{C}$ groups. $\mathrm{ABA}$ dwarfed the seedlings and made them stockier than those in other treatments (Fig. 6).

\section{DISCUSSION}

As a part of light harvesting complex, chlorophyll plays an important role in absorbing light energy and converting it to chemical energy during photosynthesis. In the present study, we observed decreased chlorophyll content under UV-C radiation, indicating the depressed ability to capture and make use of light energy under UV-C. We observed the reduced $\mathrm{Fv} / \mathrm{Fm}$, Yield and NPQ upon UV-C radiation, implying a depressed PSII performance under stress ( $\mathrm{Li}$ et al., 2009). According to the Planck constant, the shorter the wavelength, the higher the energy of the photon. UV-C depressed the activity of chlorophyll and inhibited PSII behaviour, which explains the reduced biomass accumulation. Damage to the membranes resulted in ROS generation, e.g. $\mathrm{O}_{2}^{-}$and $\mathrm{H}_{2} \mathrm{O}_{2}$, which in turn aggregated the negative effects on membrane. On the other hand, stress also triggered the self-defence system of the plant wherein the activities of SOD, POD and CAT were enhanced, as were the accumulation of flavonoids. We further investigated the responses of 4 isoflavones, which represent 2 types of isoflavones (that is, aglycons and glucosides), to UV-C and found that the contents of all 4 isoflavones were enhanced, among them daidzin and genistein, which were more responsive than genistin and daidzein under UV-C radiation.

Tossi et al (2012) demonstrated that ABA contributed to preserving cell redox homeostasis from uncontrolled ROS generation and associated deleterious effects provoked by UV-B radiation. Herein, we observed the remarkable similarities of ABA effects on soybean seedlings after UV-C treatment. We speculated that enhanced ABA reduced ROS generation and improved antioxidase activities, which alleviated the damage to the membrane including thylakoid, and hence fewer flavonoids were required. Decreased photoinhibition and enhanced photoprotection improved PSII performance, which enhances biomass accumulation. UV-C and ABA also altered soybean morphology, which resulted in dwarfed seedlings, ABA application enhanced the biomasses of the dwarfed seedlings.

\section{CONCLUSIONS}

1. UV-C treatment showed adverse effects on chlorophyll and PSII. The antioxidant system and flavonoids were involved in the soybean adaptive responses to UV-C where the activities of superoxide dismutase, peroxidase and catalase increased, and flavonoids content improved, also daidzein and genistein were significantly responsive isoflavone molecules.

2. ABA decreased reactive oxygen species generation in soybean seedlings, enhancing the antioxidant capacity of superoxide dismutase, peroxidase and catalase, and reducing flavonoid production during treatment with UV-C radiation, and finally biomass accumulation was enhanced.

Conflict of interest: The Authors do not declare conflict of interest.

\section{REFERENCES}

Akito K., Kimitsune I., Takayuki K., Hideyuki M., and Kosaku T., 2015. Abscisic acid induces biosynthesis of bisbibenzyls and tolerance to UV-C in the liverwort Marchantia polymorpha. Phytochemistry, 117, 547-553.

https://doi.org/10.1016/j.phytochem.2015.05.009

Amjad M., Akhtar J., and Yang AZ., 2014. Intergrating role of ethylene and ABA in tomato plants adaptation to salt stress. Sci. Hortic., 172, 109-116. https://doi.org/10.1016/j.scienta.2014.03.024

Asakawa Y., Ludwiczuk A., and Nagashima F., 2013. Phytochemical and biological studies of bryophytes. Phytochemistry, 91, 52-80.

https://doi.org/10.1016/j.phytochem.2012.04.012

Bradford M.M., 1976. A rapid and sensitive method for quantitation of microgram quantities of protein utilizing the principle of protein-dye binding. Anal. Biochem., 72, 248254. https://doi.org/10.1006/abio.1976.9999

Formica-Oliveira A.C., Díaz-López V., Artés F., and ArtésHernández F., 2017. Use of postharvest uv-b and uv-c radiation treatments to revalorize broccoli byproducts and edible florets. Innovative Food Sci. Emerging Technol., 43, 77-83. https://doi.org/10.1016/j.ifset.2017.07.036

Harrowven D.C. and Kostiuk S.L., 2012. Macrocyclic bisbibenzyl natural products and their chemical synthesis. Nat. Prod. Rep., 29, 223-242. https://doi.org/10.1039/c1np00080b

Hollosy F., 2002. Effects of ultraviolet radiation on plant cell. Micron., 33, 179-197. https://doi.org/10.1016/s0968-4328(01)00011-7

Jasen M.A. and Bornman J.F., 2012. UV-B radiation: from generic stressor to specific regulator. Physiol Plant, 145, 501-504. https://doi.org/10.1111/j.1399-3054.2012.01656.x

Lee H.S., 2000. Principles and Experimental Techniques of Plant Physiology and Biochemistry (in Chinese). Higher Education Press, Beijing, China.

Li P., Cheng L., Gao H., Jiang C., and Peng, T., 2009. Heterogeneous behavior of PSII in soybean (glycine max) leaves with identical PSII photochemistry efficiency under different high temperature treatments. J. Plant Physiol., 166(15), 1607-1615.

https://doi.org/10.1016/j.jplph.2009.04.013

Ma M., Wang P., Yang R., and Gu Z.X., 2018. Effects of UV-B radiation on the isoflavone accumulation and physiological biochemical changes of soybean during germination Physiological-biochemical change of germinated soybean induced by UV-B. Food Chem., 250, 259-267. https://doi.org/10.1016/j.foodchem.2018.01.051 
Mittova V., Tal M., Volokita M., and Guy M., 2002. Salt stress induces up-regulation of an efficient chloroplast antioxidant system in the salt-tolerant wild tomato species Lycopersicon pennellii but not in the cultivated species. Physiol. Plant, 115, 393-400.

https://doi.org/10.1034/j.1399-3054.2002.1150309.x

Setlow R.B., 1974. The wavelengths in sunlight effective in producing skin cancer: a theoretical analysis. Proc. Nat. Acad. Sci., USA, 71, 3363-3366. https://doi.org/10.1073/pnas.71.9.3363

Thiruvengadam M., Kim S.H., and Chung I.M., 2015. Exogenous phytohormones increase the accumulation of health-promoting metabolites, and influence the expression patterns of biosynthesis related genes and biological activity in Chinese cabbage (Brassica rapa spp. pekinensis). Sci. Hortic., 193, 136-146.

https://doi.org/10.1016/j.scienta.2015.07.007

Tossi V., Cassia R., Bruzzone S., Zocchi E., and Lamattina L., 2012. ABA says NO to UV-B: a universal response? Trends Plant Sci., 17, 510-517.

https://doi.org/10.1016/j.tplants.2012.05.007

Urban L., Charles F., Miranda M.R.D., and Aarrouf J., 2016. Understanding the physiological effects of UV-C light and exploiting its agronomic potential before and after harvest. Plant. Physiol. Bioch., 105, 1-11.

https://doi.org/10.1016/j.plaphy.2016.04.004
Vicente A.R.,Pineda C., Lemoine L., Civello P.M., Martinez G.A., Chaves A.R., 2005. UV-C treatments reduce decay, retain quality and alleviate chilling injury in pepper. Postharvest Biol. Tec., 35, 69-78.

https://doi.org/10.1016/j.postharvbio.2004.06.001

Wu X., Guan W., Yan R., Lei J., Xu L., and Wang Z., 2016. Effects of UV-C on antioxidant activity, total phenolics and main phenolic compounds of the melanin biosynthesis pathway in different tissues of button mushroom. Postharvest Biol. Technol., 118, 51-58.

https://doi.org/10.1016/j.postharvbio.2016.03.017

Yang R.C., Yang T., and Zhang H.J., 2014. Hormone profiling and transcription analysis reveal a major role of ABA in tomato salt tolerance. Plant Physiol. Bioch., 77, 23-24. https://doi.org/10.1016/j.plaphy.2014.01.015

Ye B.X., and Zhu X.C., 2007. Basic experiments of biological science (in Chinese). Higher Education Press, Beijing, China.

Zhou X., Peng J., Fan G., and Wu Y., 2005. Isolation and purification of flavonoid glycosides from Trollius lebebouri using high-speed counter-counter chromatography by stepwise increasing the flow-rate of the mobile phase. J. Chromatogr. A, 1092, 216-221.

https://doi.org/10.1016/j.chroma.2005.07.064 